\title{
Hidrolik Santrallerde Kavitasyon Olayının Neden Olduğu Arızalar ve Çözüm Yöntemleri
}

\author{
Osman Özdemir ${ }^{1 *}$, Gökhan Kahraman ${ }^{2}$ \\ ${ }^{1}$ EÜAŞ Genel Müdürlüğü, Gezende HES Işsletme Müdürlügüu, Mersin, Turkey \\ ${ }^{2}$ Munzur Üniversitesi, Mühendislik Fakültesi, Makine Mühendisliği, Tunceli, Turkey \\ *ozdemir.osman@hotmail.com ${ }^{\mathrm{D}}$, gokhankahraman@munzur.edu.tr $\mathrm{D}$, \\ Makale gönderim tarihi: 10.09.2020, Makale kabul tarihi: 29.12.2020
}

\begin{abstract}
$\ddot{O} z$
Hidrolik enerji, Dünya' daki en zengin ve en kullanışlı yenilenebilir enerji kaynaklarından biridir. Bu nedenle enerjinin sürekli üretilebilmesi için hidrolik türbinler faydalı ömürlerini kısaltan ve yorgunluk hasarlarına neden olan başlatma ve durdurma gibi birden fazla geçici durumlara karşı optimum değerlerde en iyi verimlilik düzeyinde çalıştırılmalıdır. Optimal tasarım dışı kısmi yüklerde çalışan Francis türbinlerde akış düzensizliklerinden dolayı basınç değişimleri meydana gelir. Bu basınç değişimleri hidrolik, mekanik veya yapısal bir bileşenin doğal frekansı ile çakışması durumunda rezonans nedeniyle yüksek titreşimler oluşturarak türbinin dengesiz (balanslı) çalışmasına sebep olmaktadır. Bu çalışmada, Francis türbinin yüksek titreşimleri, türbin ayar kanadına montaj edilen kavitasyon sensörü aracılığıyla sürekli (online) titreşim izleme sistemi yardımıyla izlenerek dengesizlik durumunda çalışmasının kavitasyon titreşim etkileri ile dengesizlik giderildikten sonraki durumda kavitasyon titreşim etkileri incelenmiştir. Hidrolik türbinlerin farklı işletme şartlarında kavitasyon olayının sebep olduğu titreşim grafiksel olarak gösterilmiştir. Makalenin son kısmında verilen grafikte yatak arızası giderildikten sonra titreşim büyüklüğünün $2 \mathrm{~mm} \mathrm{~s}^{-1}$, den $0,5 \mathrm{~mm} \mathrm{~s}^{-1}$,ye düşürüldüğü görülmektedir. Bu durum hidrolik türbinlerin güvenli kavitasyon bölgesinde çalıştırılarak yüksek titreşim seviyelerinden kaçınmak için önemli bir sonuç oluşturmaktadır.
\end{abstract}

Anahtar Kelimeler: Hidroelektrik santral, kavitasyon, yenilenebilir enerji

\section{Faults Caused by Cavitation in Hydraulic Power Plants and Solution Methods}

\begin{abstract}
Hydraulic energy is one of the richest and most useful renewable energy sources in the world. For this reason, hydraulic turbines must be operated at optimum efficiency levels against multiple transient situations such as starting and stopping that shorten their useful life and cause fatigue damages in order to generate energy continuously. Pressure variations occur due to flow irregularities in Francis turbines operating at non-optimal partial loads. If the sepressure variations coincide with the natural frequency of a hydraulic, mechanical or structural component, they create high vibrations due to resonance, causing the turbine to operate in an unbalanced (balanced) manner. In this study, the high vibrations of the Francis turbine were monitored with the help of a continuous (online) vibration monitoring system via the cavitation sensor mounted on the turbine adjustment blade and the cavitation vibration effects of the operation in the case of unbalance and the cavitation vibration effect after the imbalance was eliminated. Vibration caused by the cavitation phenomenon in different operating conditions of hydraulic turbines has been shown graphically. In the the graphic given in the last part of the article, it is seen that vibration magnitude is reduced from $2 \mathrm{~mm} \mathrm{~s}^{-1}$ to $0.5 \mathrm{~mm} \mathrm{~s} \mathrm{~s}^{-1}$ after the bearing failure is eliminated. This is an important consequence for the hydraulic turbines to be operated in the safe cavitation zone to avoid high vibration levels.
\end{abstract}

Keywords: Hydroelectric power plant, cavitation, renewable energy GİRIȘ

Hidroelektrik santraller ülkeler için çok önemli temiz enerji kaynakları olmakla birlikte doğaya

karbon salınımları hemen hemen hiç yoktur (Rahi ve Kumar, 2016; Jawahara ve Micheal, 2017; Moran ve 
ark., 2018). Hidroelektrik enerji, kurulu güç ve üretim verimliliği açısından farklı enerji kaynakları ile karşılaştırıldığında en verimli, çevre dostu ve ekonomik kaynağ1 göstermektedir (Qadir ve ark.,2019). 2019 Dünya Bankas1 istatistiklerine göre yenilenebilir enerji kullanımının içinde en yüksek kullanımı \%65 ile hidroelektrik enerji oluşturmaktadır. Hidroelektrik enerjinin rolü, enerji

piyasasına diğer yenilenebilir kaynakların yoğun girişi ile son yıllarda değişmiştir (Valentin ve ark., 2019). Örneğin güneş ve rüzgâr enerjisi gibi uçucu enerji kaynakları, şebeke stabilizasyonu açısından çok daha fazla çaba gerektirir. Bu, spot piyasada düşen bir fiyat ve daha yüksek bir kontrol gücü fiyat seviyesine yol açar. $\mathrm{Bu}$ nedenle, birçok hidroelektrik santrali operatörü dengeleme enerji piyasasında rekabet etmeye yönelmiştir. Buna göre, geniş bir güç aralığında kullanılabilen Francis türbinleri elektrik şebekesine regülasyon gücü sağlamak için tasarım dışı koşullarda daha sık çalışmaktadır (Unterluggauer ve ark., 2019). Tasarım dıșı bölgede çalıșması sonucunda hidroelektrik santrallerindeki (HPP'ler) güç salınımları ve titreşimler gibi problemler elektrik güç üretim birimlerinin işletiminde kullanılan Francis türbinlerde sıklıkla görülebilir (Brezovec ve ark., 2019). Zhang ve arkadaşları salınım analizi yaparak salınım mekanizması ve sistemin kararlı ve kararsız titreşimi arasındaki temel farklılıkları ayrıntılı olarak açıklamışlardır (Zhang ve ark., 2019). Kahraman ve arkadaşları tasarım dışı yüklerde çalışan hidrolik makinelerde kavitasyon, akış dengesizlikleri, aşırı titreşimler, malzeme yüzeylerinde hasar ve makine performansinın bozulmasi gibi istenmeyen sonuçlarını açıklamışlardır (Kahraman ve ark., 2019). Online izleme sistemi ile izlenen türbinlerde Zhang ve arkadaşları kaplan türbin kanadının olağan dışı bir arızasını izleme sistemi ile titreşim seviyelerinde ani bir artış tespit ettikten sonra türbini kontrol ederek çark kanadı üzerinde büyük bir çatlak oluştuğu ve çark kanadının uç kısmının da kırılmış olduğunu görmüşlerdir (Zhang ve ark., 2019). Presas ve arkadaşları ünitenin birden fazla başlatma ve durdurmanın neden olduğu çarkın yorgunluk hasarın1, kavitasyon ve vortex (girdap) olgularını incelemişlerdir (Presas ve ark., 2019). Trivedi ve arkadaşları bir hidroelektrik santralde değişken hızlı teknolojinin kullanılarak kavitasyon üzerinde sınırlayıcı etkisi üzerine çalışma yapmışlardır (Trivedi ve ark., 2020). Bir malzemenin kavitasyona direnme yeteneği bilgisi, bir Francis türbininde kullanım için ne kadar uygun olduğunu tanımlamada önemli olduğunu belirterek, Francis tipi türbin malzemesi olarak düşük alaşımlı çelik ve paslanamaz çeliği karşılaştırmıştır. $\mathrm{Bu}$ karșılaştırma sonucunda düşük alaşımlı çeliğin paslanmaz çelikten dört kat daha hızlı aşındığını kanıtlamışlardır (Ylönen ve ark., 2018).

$\mathrm{Bu}$ makalede Francis tipi türbinin yüksek salınım altında çalışırken türbinin maruz kaldığı kavitasyon titreşim genliği ile salınımın azaltılmas1 durumundaki kavitasyon titreşim genliğinin analizi yapılarak, Francis türbinlerinde salınımın düşürülmesinin türbinin kavitasyon olgusuna olan faydası ispatlanmıştır.

\section{Hidroelektrik Santral Çalışma Prensibi ve Hidroelektrik Türbin Tipleri}

Hidroelektrik santrallerin çalışma prensibi Şekil 1'de gösterildiği gibi akmakta olan suyun önüne, suyun toplanması için baraj inşa edilir ve bu kurulan baraj sayesinde su biriktirilir. Toplanan ve durgun haldeki su kütlesi potansiyel enerjiye sahiptir. Potansiyel enerjiye sahip olan su kütlesi belli bir düşüden belli bir hizla cebri borular vasitası ile türbinlere gönderilir. Suyun durgun haldeki potansiyel enerjisi, aşağıya akmaya başlayınca kinetik enerjiye dönüşür. Akan su türbin çarkına çarpması ile kinetik enerji mekanik enerjiye dönüşür. Üretilen enerjiyi belirlemek için türbin çarkına çarpan su miktarı ayar kanatları ile ayarlanır. Ayar kanatları servomatorlara bağlı ayar çemberi ile kontrol edilir. Servomotorlar basınçlı yă̆ ile çalışır, basınçlı yağın gönderilmesini de hız regülâtörü kontrol eder. Su türbinlerde dönme hareketine başlar ve oluşan mekanik enerji jeneratörler ile elektrik enerjisine dönüşür. 


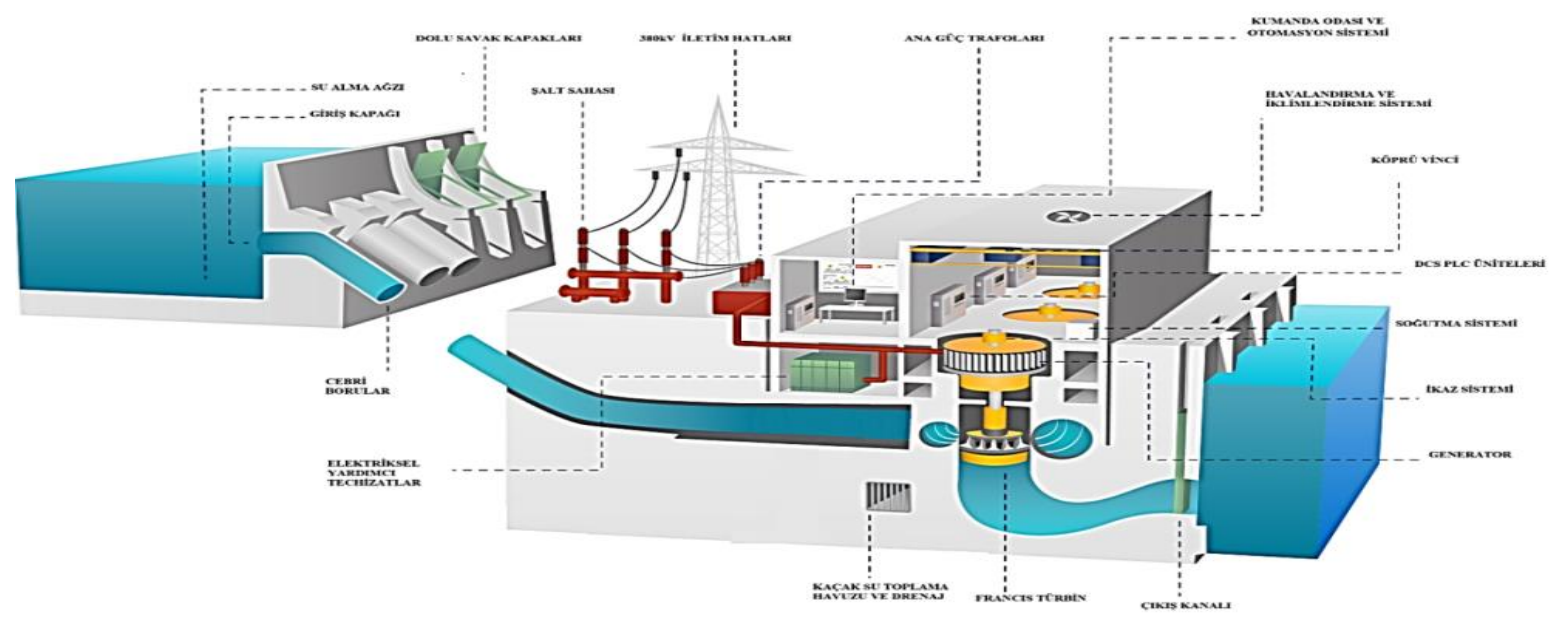

Şekil 1. Hidroelektrik santral çalışma şeması

İmpuls ve reaksiyon türbinleri olmak üzere iki ana tür hidrolik türbin vardır. Bir proje için seçilen hidroelektrik türbinin tipi su yüksekliğine (basma yüksekliği) bağlıdır; impuls türbini, türbin çarkını hareket ettirmek için genellikle suyun hızını kullanır ve atmosferik basınca boşalır. Su akışı, çark üzerindeki her kovaya çarpar. Türbinin olumsuz tarafında emme yoktur ve su çarka çarptıktan sonra türbinin emme borusundan dişarı akar. Bir impuls türbini genellikle yüksek düşü, düşük akış uygulamaları için uygunken, reaksiyon türbini basınç ve hareketli suyun birleşik etkisinden güç geliştirir (Gondal ve ark., 2019). Çalışmamızı yaptığımız hidroelektrik santralde her biri yaklaşık 160 MW gücünde olan 8 adet Francis türbini bulunmaktadır.

İmpuls türbinleri sınıfina giren pelton türbini ile reaksiyon türbini sınıfına dahil olan kaplan ve francis türbinine ait genel özellikler aşağıda belirtilmiştir.

\section{Pelton türbini}

Pelton tipi hidrolik türbinler, serbest püskürtmeli türbinler olarak sınıfladırılmışlardır. Aşırı yüksek hidrolik düşü ve az değerli su debilerine sahip yerlerde bu türbin tipinden faydalanılmaktadır. Şekil 2'de gösterildiği gibi pelton hidrolik türbinlerinin düze memelerinden fışkırtılan su pelton türbin çarklarının çevresinde bulunan kepçelere çarparak suyun mevcut kinetik enerjisi mekanik enerji haline geçmesiyle rotoru dönmeye başlar.

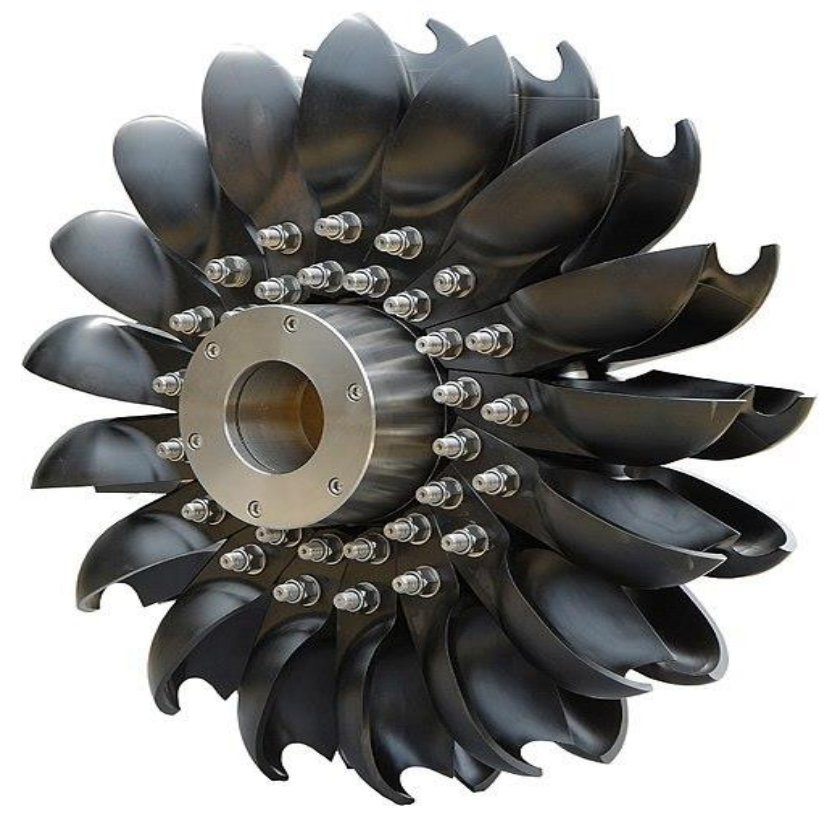

Şekil 2. Pelton türbini (URL-1, 2020)

\section{Kaplan türbini}

Kaplan tipi türbinlerin özgül hızları yüksek olup, yüksek debilerde fakat düşük düşü değerlerinde çalışırlar. Bu tip türbinlerin verimli olabileceği ortalama düşü değeri 80 m'nin altındadır. Şekil 3'de gösterildiği gibi Kaplan türbinlerinin kanatların açısı (veya eğimi) tüm çalışma noktaları için iyi bir performans sağlamak için insidans akış açısını değiştirebilen birkaç bıçaktan oluşur (Zhang ve ark., 2019). Kaplan türbinleri salyangoz gövdeli veya boru tipli olarak üretilirler. 


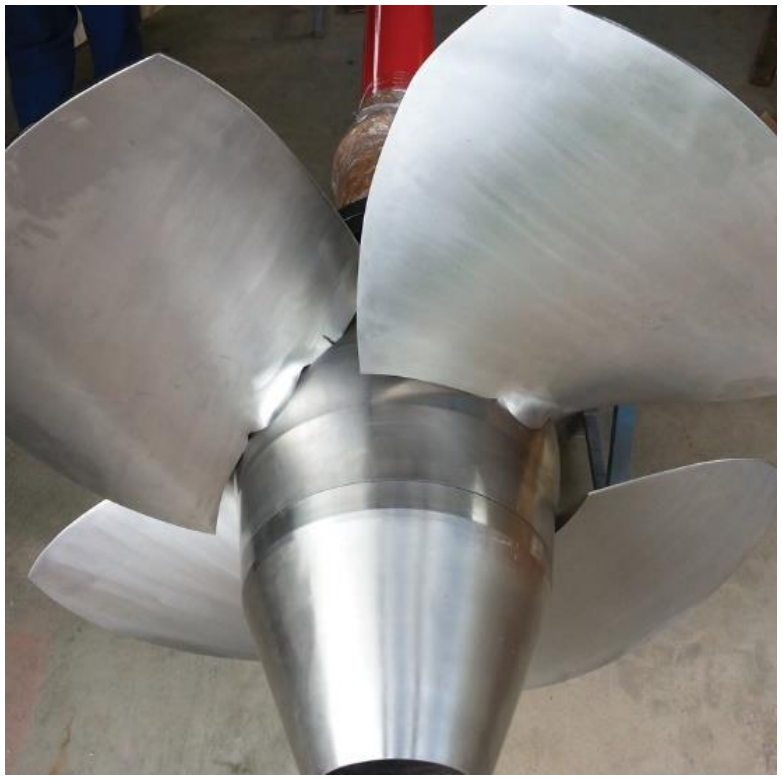

Şekil 3. Kaplan türbini (URL-2, 2020)

\section{Francis türbini}

Francis tip türbinlerde suyun türbin çarkına her yönden eşit basınçta girmesini sağlayan salyangozda yönlendirilen su akışı, açısal momentumla Şekil 4'de gösterildiği gibi sabit kanatlara buradan devir sayıs1güç ayarının yapıldığı ayar kanatları arasından geçerek türbin çarkının kanatlarına çarparak, çarkın ve buna bağlı kütlenin dönmesini sağlar. Çarkı terk eden su emme borusundan geçer ve suyun kinetik enerjisini statik geri basınca dönüştürür.

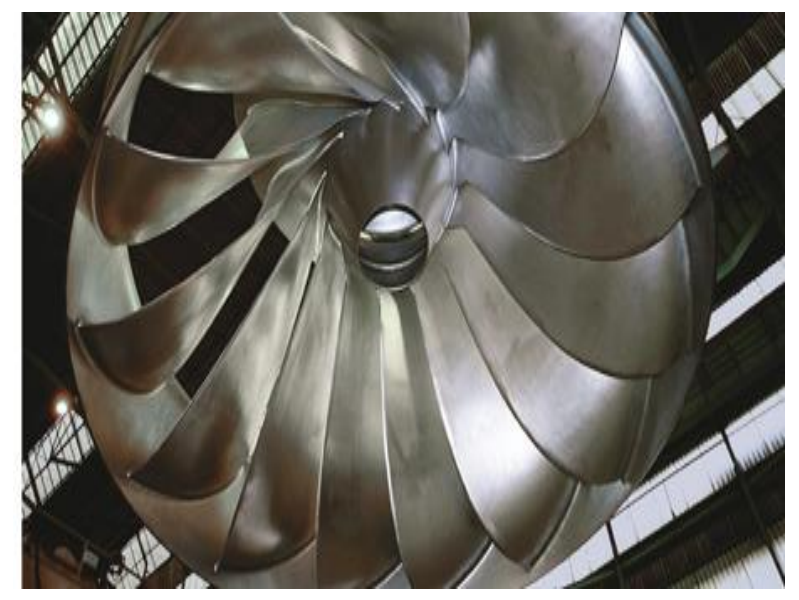

Şekil 4. Francis türbini (URL-3, 2020)

Düşü ve özgül hız değerlerine göre kullanılacak impuls ve reaksiyon tipi türbin tiplerinin seçilmesine ait bilgiler Çizelge 1'de gösterilmiştir.
Çizelge 1. Hidrolik düşü ve özgül hıza göre türbin tipleri

\begin{tabular}{|c|c|c|}
\hline $\begin{array}{c}\text { Türbin } \\
\text { Tipi }\end{array}$ & $\begin{array}{c}\text { Düşü Aralığı } \\
(\mathbf{m})\end{array}$ & $\begin{array}{c}\text { Özgül hız } \\
(\mathbf{n q})\end{array}$ \\
\hline Francis & $10<\mathrm{H}<350$ & $80-400$ \\
\hline Kaplan & $2<\mathrm{H}<60$ & $340-1000$ \\
\hline Pelton & $60<\mathrm{H}<1300$ & $12-30$ \\
\hline
\end{tabular}

\section{Kavitasyon Olayı}

Kavitasyon olay1, hidrolik türbinlerde son derece yaygın olan ama hiç görülmesi istenmeyen bir olay olup, hidroelektrik santrallerde vibrasyona, performans azalmasına bağlı olarak verimin düşmesine ve türbini oluşturan malzemelerde hasarlara neden olmaktadır. Kavitasyon, Knapp tarafindan bir sıvının sabit sicaklıkta sıvının buhar basıncına dinamik basınç düşüşleri nedeniyle buhar boşluklarının oluştuğu ve büyüdüğü bir duruma ulaştığı durum olarak tanımlanır (Escelera ve ark., 2006). Akışkan sıvının hidrodinamik basıncı buhar basıncının altına düşmesi sonucunda buhar fazına geçer (Saçma ve ark., 2017). Bu bölgede öz kütleleri birbirlerinden farklı maddelerin (su ve su buharı) birbirine karışması ile çift fazlı bir akış meydana gelecektir. Çift fazlı akış içerisinde bulunan su ve su buharı özgül ağırlıklarının birbirinden farklı olduğundan dolayı bu bölgedeki su ve su buharının akış hızları da birbirinden farklı olacak dolayısıyla öz kütlesi suya göre daha düşük olan su buharının, karışım içerisindeki hızı da su hızına göre düşük olacağından su buharı tanecikleri suyun akışına uyum sağlayamayarak geride kalacak ve geriden akmakta olan su tanecikleri ile çarpışması sonucunda daha önceki bölümlerde mevcut olan düzenli akış rejimi bu bölgede dengesiz hale gelir ve gürültülü, türbülanslı (karışık) bir akış oluşur (Başeşme, 2003). Türbülanslı akım içerisindeki su ve su buharı zerreciklerinin çark kanat yüzeyine vurmasıyla oluşan küçük kabarcıkların yüksek basınç bölge alanına geçiş yaptığında ani olarak ortadan kalkması olayına kavitasyon denir.

Kavitasyon, reaksiyon hidrolik türbinlerinde ki aşındırıcı erozyonun en önemli nedenlerinden biridir Tiwaria ve ark., 2020). Kavitasyon hidrolik türbinlerin güvenliği için daha fazla basınç dalgalanmalarına neden olabilecek en zararlı faktörlerden biridir (Yu ve ark., 2020). Kavitasyon, 
Kaplan, Francis ve Pump-Turbine gibi reaksiyon suyu türbinlerinde önemli bir rol oynar. Kaplan ve Francis türbinleri arasındaki temel fark, sirasıyla eksenel ve radyal olan türbin çarkının tasarımıdır (Escelera ve ark., 2006).

Kavitasyon olayının türbin çark kanadında meydana getirdiği hasar ve gözenekler Şekil 5'te görülmektedir.

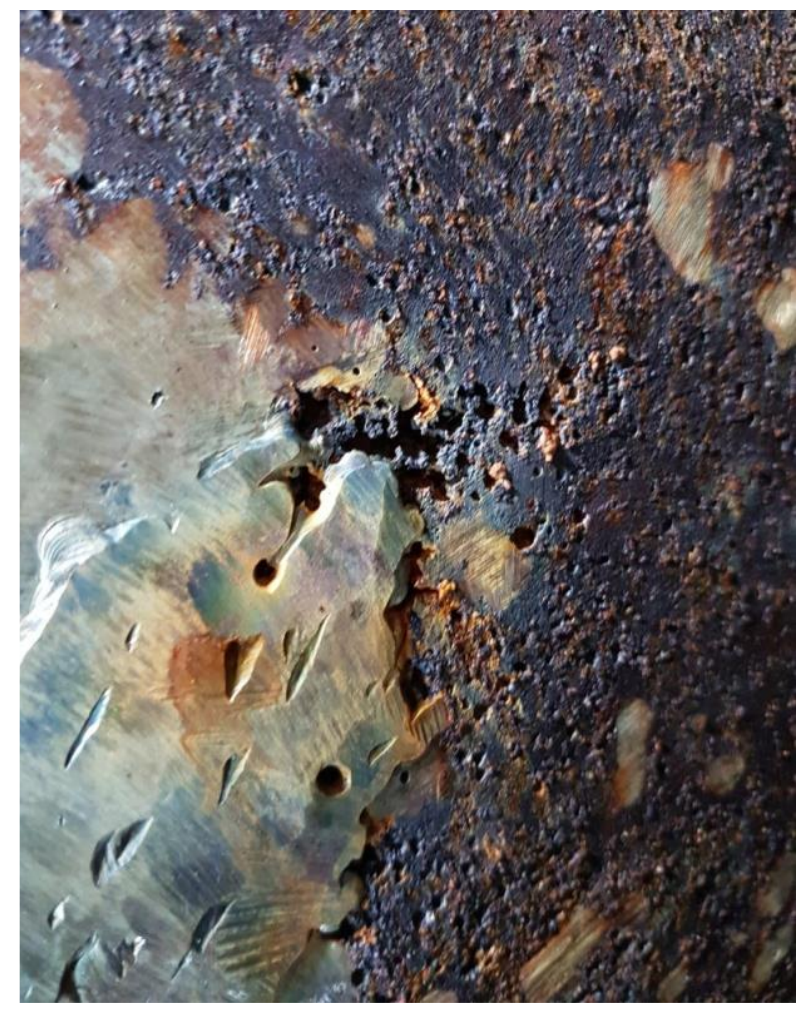

Şekil 5. Kanat yüzeyindeki kavitasyon gözenekleri ve hasarın görünüş

Yukarıda tanımı yapılmış olan hidrolik türbindeki kavitasyon olayının başlıca ana nedenleri aşağıdaki koşullardan kaynaklanıyor olabilir.

1. Türbinin tasarım profili.

2. Tesisin çeşitli yük gereksinimlerini karşılamak için çalışma koşullarında sık sık değişiklik yapılması (Dorji ve Ghomashchi., 2014).

Hidrolik makinelerde kavitasyon, akış yüzeylerinde hasar ve makine performansinın bozulması (Abbas ve ark., 2019) maliyet artışı, tam yükte ve kısmi yüklerde açma ve makinelerin etki verimliliğinde düşüş gibi istenmeyen sonuçlar doğurmaktadır (Gondal ve ark., 2019).

Hidroelektrik santrallerde kavitasyon olayını olumsuz yönde etkileyen etkenlerden biride türbinlerde meydana gelen salınım olayıdır. Üniteler enterkonnekte şebekenin ihtiyacını karş1lamak için ani ve değişken güç değerlerinde çalışması sonucunda türbin taşıyıcı yatak ve türbin kılavuz yatak ayarlarında bozulman ortaya çıkması salınım olayına yol açar. Türbinin tasarım dışı koşullarda çalışması sonucunda ortaya çıkan salınım ve kavitasyon arasında yakın bir ilişki vardir.

\section{MATERYAL VE METOT}

Online Vibrasyon Sistemi ile Kavitasyon Analizi

Titreşim İzleme Sistemi analizini kullanarak makinenin çalışma aralığının dışında çalışması durumunda titreşime bağlı olarak arızayı zamanında tespit ederek arızaya müdahale edilmesinde oldukça faydalı bir tekniktir. Mohanta ve arkadaşları Titreșim İzleme Sistemi ile hasarı ve arıza olasılı̆̆ını en aza indirerek Hidrolik Üretim Ekipmanının performansını arttıracağını, böylece ekipman daha uzun süre kullanılabileceğini açıklamışlardır (Mohanta ve ark., 2017).

Yapılan çalışmada, hidroelektrik santralde kurulu bulunan Brüel \& Kjær Vibro marka Vibrocontrol 6000 koruyucu titreşim izleme sistemi ve Compass diyagnostik titreşim analiz yazılımı kullanılmıştır. VCM ile 150-155 MW güç ile çalışan 166,7 $\mathrm{d} \mathrm{dak}^{-1}$ ile dönen Francis türbininde Şekil 6 ve Şekil 7'de türbin kombine yatağından gelen $\mathrm{x}$ ve y yönlü verilere göre salınım kaynaklı dengesizlik arızasının tespiti yapılmış olup bu durumda koruyucu titreşim izleme sistemi ile kavitasyon genliği takibi yapılmıştır. 


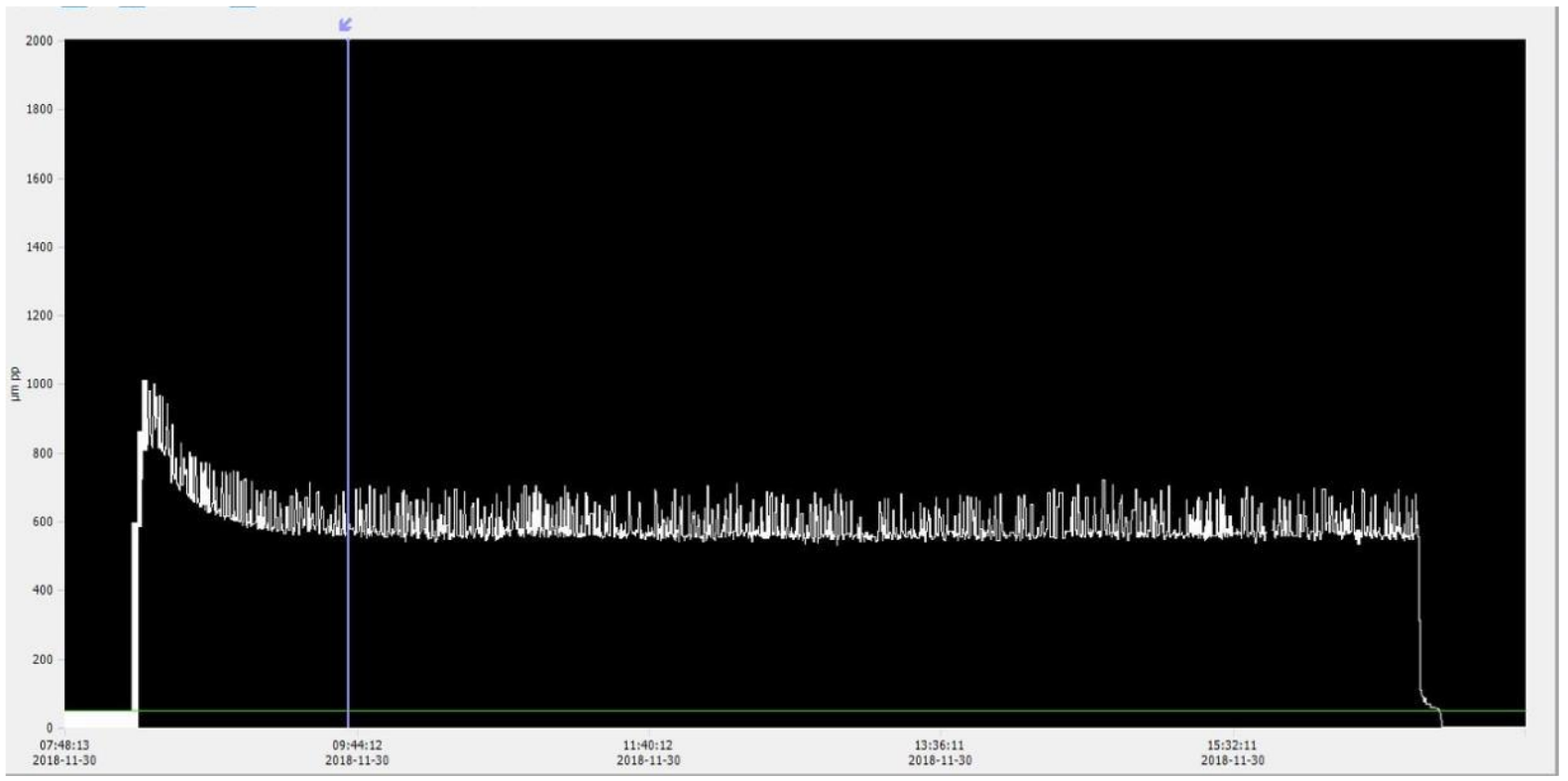

Şekil 6. Balans öncesi ünite 150-155 MW kısmi yükte çalışırken türbin kombine yatağı izafi şaft titreşimi (x yönlü) salınım grafiği

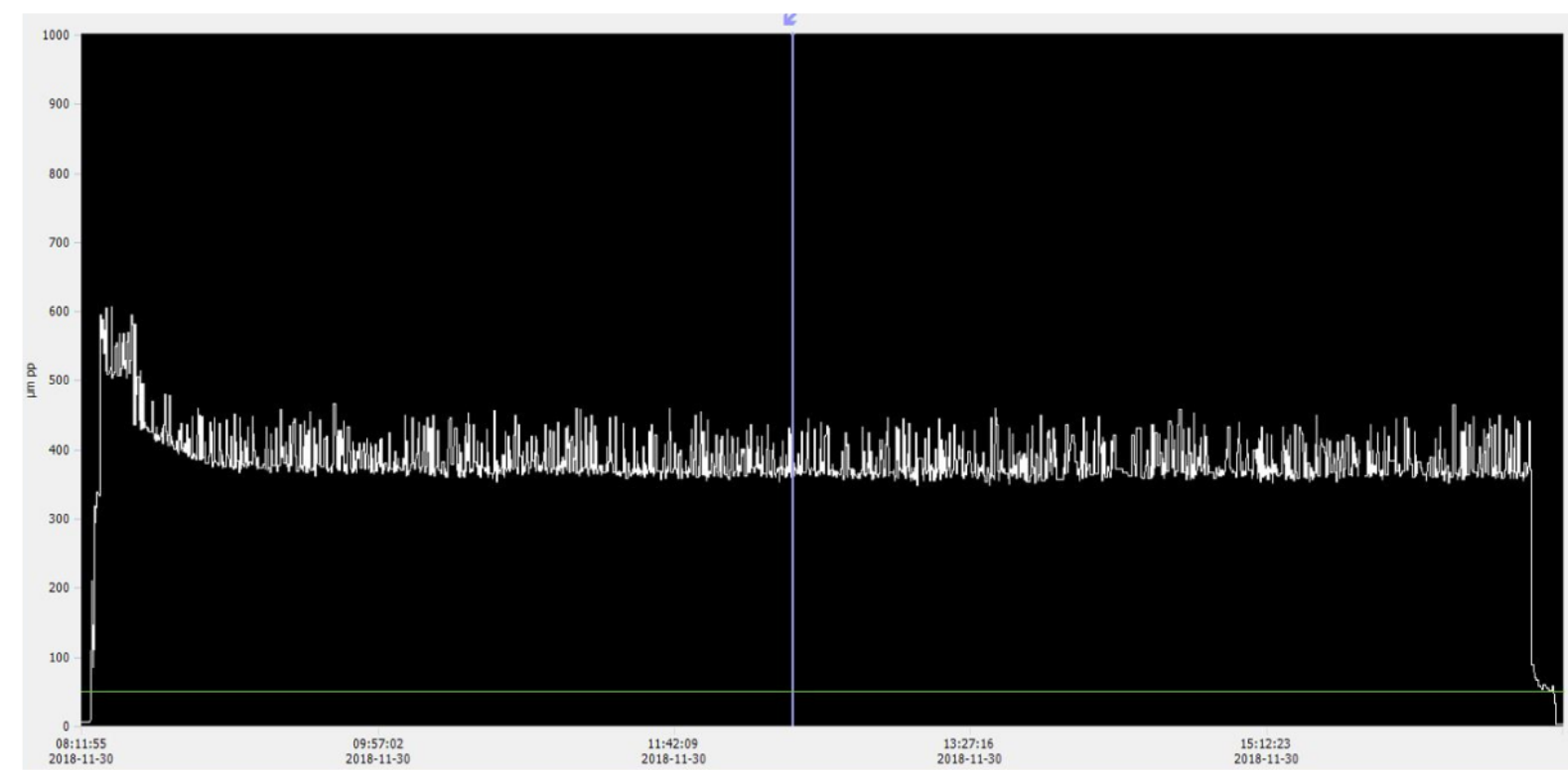

Şekil 7. Balans öncesi ünite 150-155 MW kısmi yükte çalışırken türbin kombine yatağı izafi şaft titreşimi (y yönlü) salınım grafiği

Daha sonra dengesizlik arızası giderildikten sonraki Şekil 8 ve Şekil 9'da türbinin kombine yatağından gelen $\mathrm{x}$ ve y yönlü salınım değerlerine türbinin çalışma değerleri getirildikten sonra kavitasyon genliği takibi yapılarak salınımın kavitasyona olan etkisi incelenmiştir. 


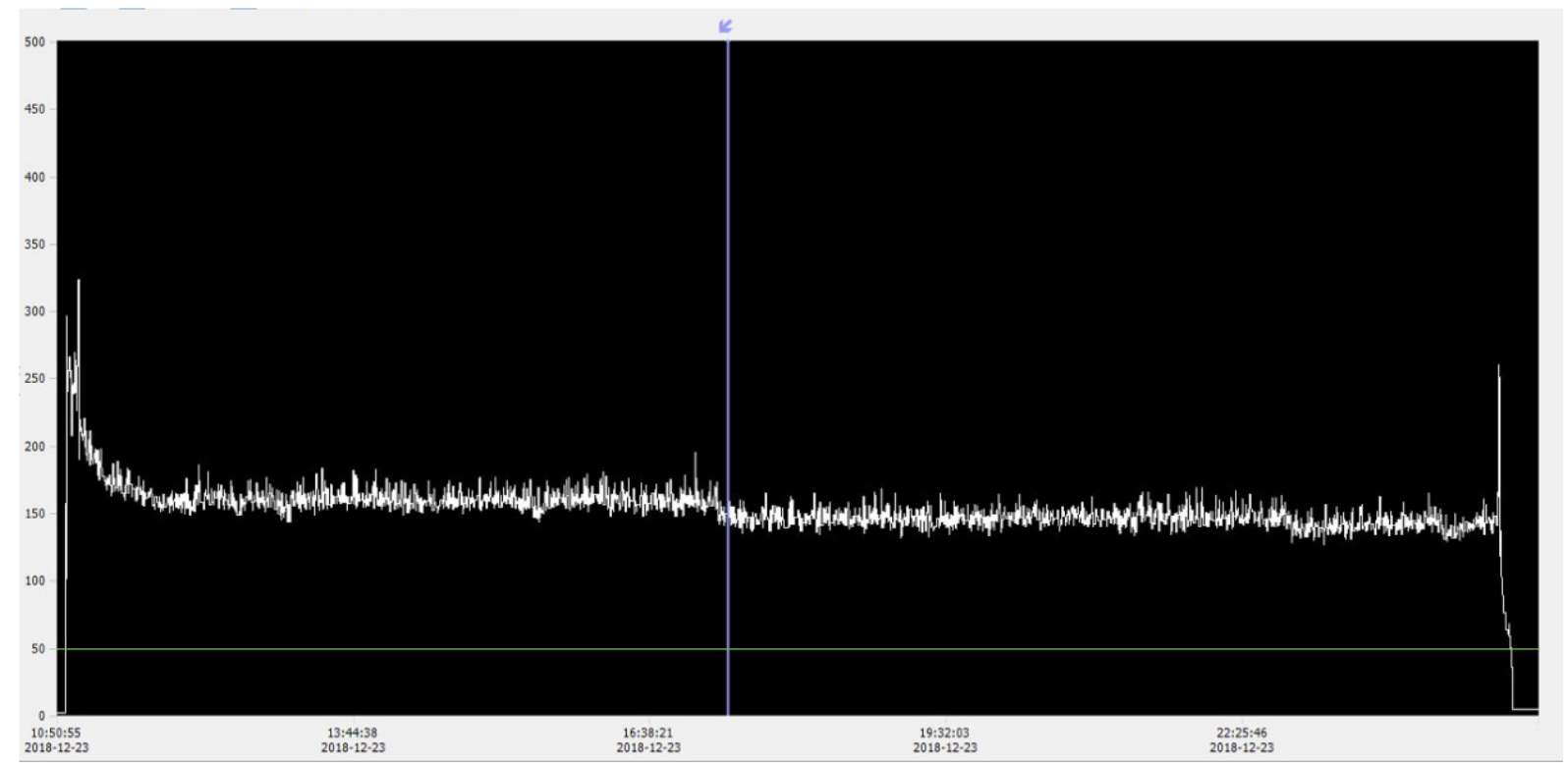

Şekil 8. Balans çalışması sonrası ünite 150-155 MW kısmi yükte çalışırken türbin kombine yatağı izafi şaft titreşimi (x yönlü) salınım grafiği

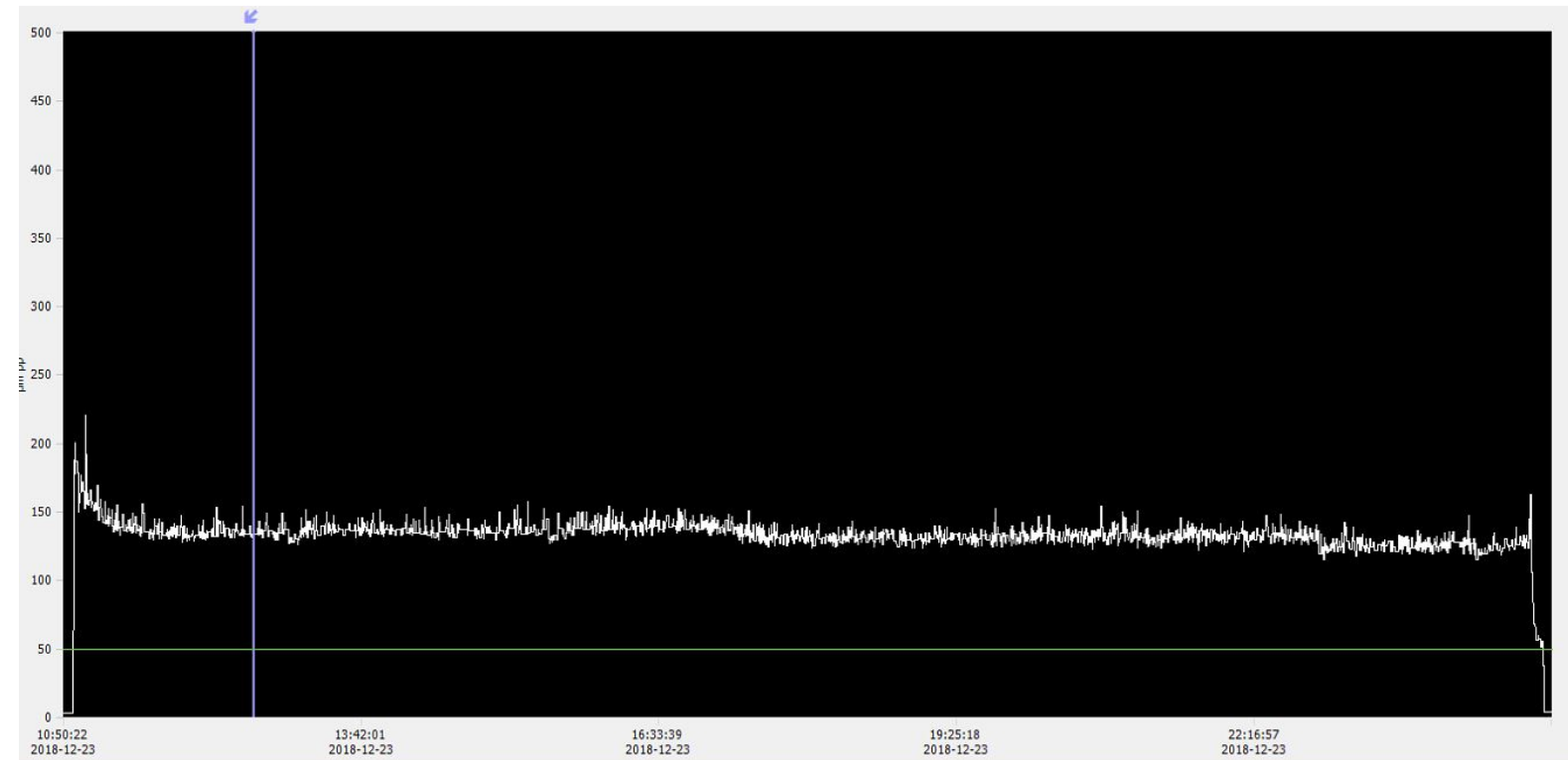

Şekil 9. Balans sonrası ünite 150-155 MW kısmi yükte çalışırken türbin kombine yatağı izafi şaft titreşimi (y yönlü) salınım grafiği

Kavitasyon olgusu emme borusundaki titreşimlerin yüksek frekanslı bileşenlerinin filtrelenmesi yolu ile ölçülmektedir. Emme borusu cidarına veya ayar kanat eksenine yerleştirilen yüksek frekans tepkisine sahip pizoelektrik tip titreşim ivme sensörü kullanılarak alınan veriler online izleme sistemine gönderilmiştir. Şekil 10'da görüldüğü gibi ayar kanadına yerleştirilen AS-063 pizoelektrik ivme sensörü ile ölçüm yapılmıştır. 


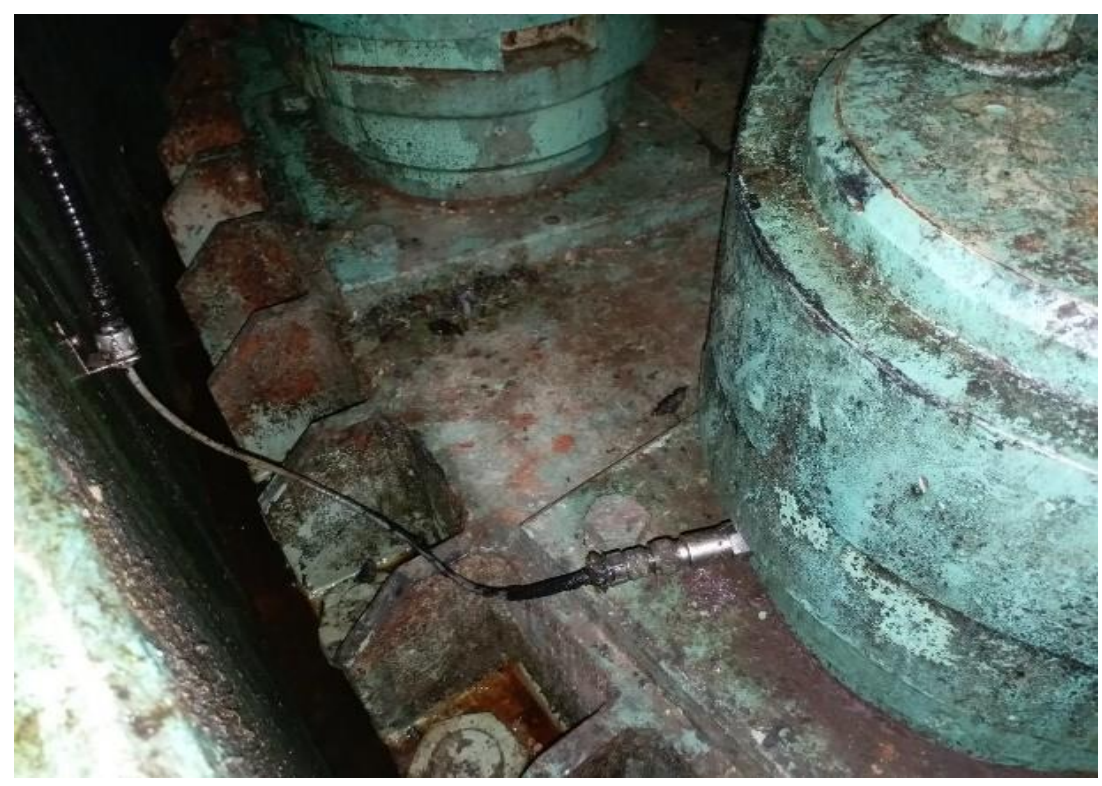

Şekil 10. Türbin ayar kanadına montaj edilen AS- 063 kavitasyon sensörü

\section{BULGULAR}

Hidrolik türbinler enerji üretmek için ilk olarak nominal devir sayısının \%20'si değerinde döndürülürler. $\mathrm{Bu}$ duruma boşta çalışma durumu denir. Daha sonra şartlar uygunsa ikaz enerjisi verilir. Tam bu anda senkronizasyon şartları gerçekleştirilerek elektrik şebekesine bağlanır. Bağlantı tamamlandıktan sonra yük almaya başlar. Hidrolik türbin nominal yüke ulaşana kadar türbin şaftı farklı titreşim değerlerine maruz kalır. $\mathrm{Bu}$ süreçte titreşim frekansına en büyük etkiyi kavitasyon olayının sebep olduğu darbeler gösterir.

Şekil 11'de hidrolik türbin 0 MW'dan 150 MW'a yüklenirken oluşan kavitasyon şiddetinin sebep olduğu titreşim seviyesinin balans arızası öncesi ve balans arıası giderildikten sonraki durumu görülmektedir

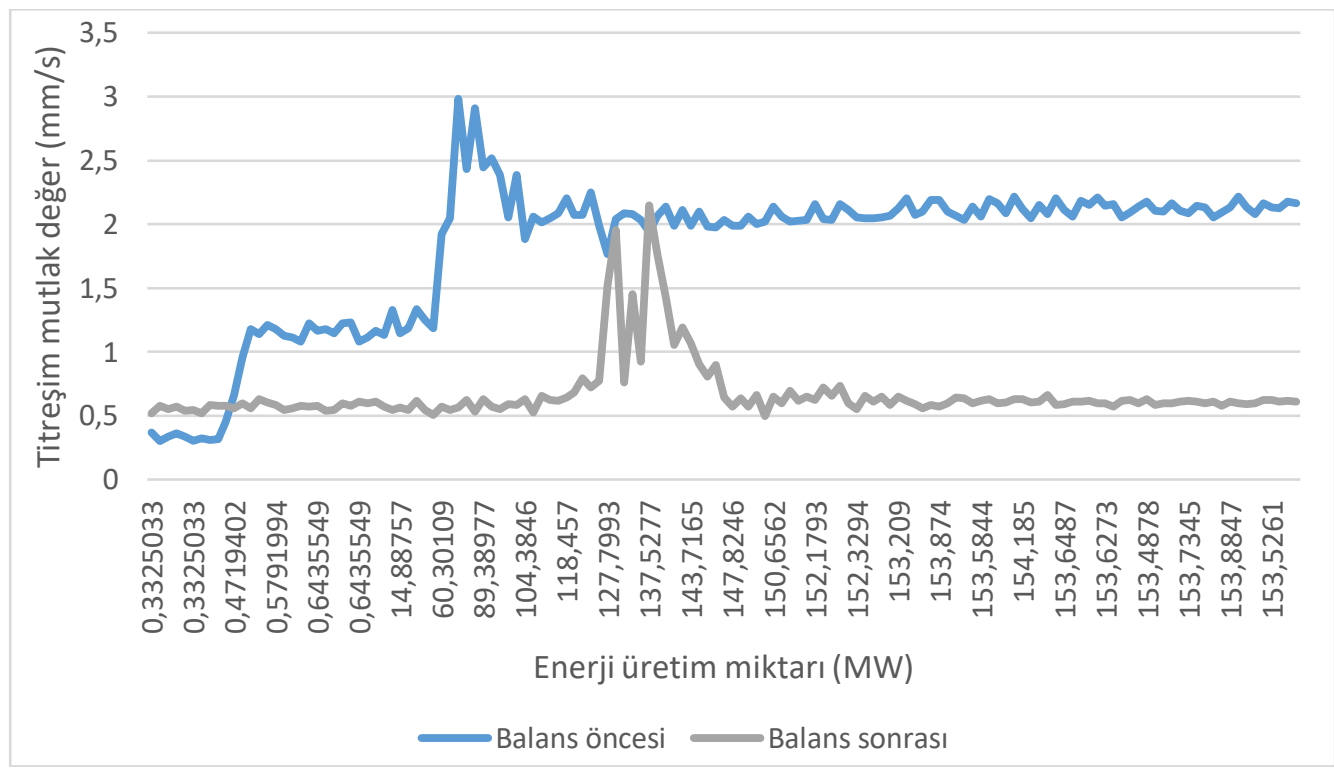

Şekil 11. Balans öncesi ve balans çalışma sonrası kavitasyon olayı etkisinin değişim grafiği 
Balans öncesi yüksek titreşim ile çalş̧an türbinde kavitasyon olayının ünite ilk devreye alındığı zamandan başlayarak titreşime bağlı en büyük hasarın 70-90 MW arasında max. $3 \mathrm{~mm} \mathrm{~s}^{-1}$ 'lik bir titreşime ulaşarak peak noktaya ulaştı̆̆ 1 ve $130 \mathrm{MW}$ sonrası 2 $\mathrm{mm} \mathrm{s}^{-1}$ lik bir titreşimle sabit hale geldiği görülmektedir.

Yapılan balans çalş̧ması sonrası türbinin çalıştırılması durumunda ise ünitenin devreye alındıktan sonra düşük titreşim frekansı ile çalışmaya devam ettiği ve kavitasyon olayının $120-145$ MW arasındaki bölgede max. $2 \mathrm{~mm} \mathrm{~s}^{-1}$ lik bir titreşim seviyesine maruz kaldıktan sonra $0.5 \mathrm{~mm} \mathrm{~s}^{-1}$ lik titreşim değerine düşerek sabit hale geldiği görülmektedir.

\section{SONUÇLAR VE TARTIŞMA}

Hidrolik türbinlerde kavitasyonun tamamen önüne geçilmesi zordur. Fakat ekonomik olarak kabul edilebilir seviyeye indirilebilir. Araştırmacılardan bazıları, türbin bileşenleri tasarım değişikliklerine ve türbin kanatlarına farklı materyal ve kaplamalar yapılmasını incelemişlerdir. $\mathrm{Bu}$ incelemeler sonucunda, çoğu durumda iyileşmenin önemli olmadığını bildirmişlerdir. $\mathrm{Bu}$ nedenle; Hidrolik türbinlerde kavitasyonun etkisini yok etmek yerine zararını azaltmak için çalışmak, bu konuda gerekli deneysel ve teorik çalışmaları yapmak daha uygun görülmektedir. Bu çalışmada iki sonuç elde edilmiştir. Birincisi, hidrolik türbinlerde meydana gelen dengesizlik arıası ile birlikte kavitasyon olayının şiddetinin aşırı arttırmasından dolayı bu durumun giderilememesi durumunda daha büyük arızalara sebep olacağı açıktır. $\mathrm{Bu}$ durum büyük maliyetli arızalara sebep olacaktır. İkinci sonuç ise, hem dengesizlik arızası esnasında, hem de arıza giderildikten sonra ünite 0 MW'dan 155 MW civarlarına yük alırken kavitasyon olayının şiddeti gözlemlenmiştir. Hangi yüklerde kavitasyon olayının daha fazla etkili olduğu tespit edilmiştir. Bu sonuçlar hidrolik türbin-generatör ünitelerinin sağlıklı ve sürekli işletilebilmesi açısından büyük önem arz etmektedir. Ayrıca bu çalışmanın devaminda hidroelektrik santrallerde kavitasyon olayının şiddetinin belirlenmesinde matematiksel model oluşturarak simülasyonlarla farklı işletme şartlarında daha net sonuçlar elde edilebilir.

\section{ÇIKAR ÇATIŞMASI BEYANI}

Yazar bu çalışmasında herhangi bir şekilde çıkar çatışması olmadığını beyan eder.

\section{ARAŞTIRMA VE YAYIN ETIĞ́̆ BEYANI}

Yazar bu çalışmasında araştırma ve yayın etiğine uyulduğunu beyan eder.

\section{KAYNAKLAR}

Abbas, I.A., Qandil, D.M., Al-Haddad, R.M., Amano, S.R., 2019. Performance investigation of very-low-head kaplan hydro-turbines. AIAA SciTech Forum, San Diego California,United States, January 7-11.

Başeşme, H., 2003. Hidroelektrik Santrallar ve Hidroelektrik Santral Tesisleri, DSİ Yayınları, Ankara.

Brezovec, M., Kuzle, I., Krpan, M., Holjevac, N., 2019. Analysis and treatment of power oscillations in hydro power plant Dubrava. IET Renewable Power Generation The Institution of Engineering and Technology, 14(1):80-89.

Dorji, U., Ghomashchi, R., 2014. Hydro turbine failure mechanisms. Engineering Failure Analysis, 44:136147.

Escalera, X., Egusquizaa, E., Farhat, M., Avellan, F., Coussirat, M., 2006. Detection of cavitation in hydraulic turbines. Science Direct, 20:983-1007.

Gondal, T.M., Hameed, Z., Shah, M.U., Khan, H., 2019. Cavitation phenomenon and its effects in Francis turbines and amassed adeptness of hydel power plant. International Conference on Computing, Mathematics and Engineering Technologies ICOMET, NCKU, Tainan, Taiwan, June 24-29.

Jawahara, C.P., Michael, P.A., 2017. A review on turbines for micro hydropower plant. Renewable and Sustainable Energy Reviews, 72:882-887.

Kahraman, G., Yücel, H.L., Taşgin Y., 2019. Identification of optimum working conditions in hydro electric power plants for cavitation. Engineering Failure Analysis, 96:168-174.

Moran, E.F., Lopez, M.C., Moore, N., 2018. Sustainable hydropower in the 21st century. Proceeding of the National Academy of Sciences of the United States of America, 115(47):11891-11898.

Mohanta, R.K., Chelliah, T.R., Allamsetty, S., Akula, A., Ghosh, R., 2017. Sources of vibration and their treatment in hydro power stations. Engineering Science and Technology, an International Journal, 20:637-648.

Presas, A., Luo, Y., Wang Z., Guo B., 2019. Fatigue life estimation of Francis turbines based on experimental strain measurements. Renewable and Sustainable Energy Reviews, 102:96-110.

Rahi, O.P., Kumar, A., 2016. Conomic analysis for refurbishment and uprating of hydropower plants. Renewable Energy, 86:1197-1204.

Saçma, S., Eskikale, T., Orhon, B.E., 2017. Francis türbinlerinde döner girdap halatının titreşim 
ölçümleriyle belirlenmesi. VIII. Bakım Teknolojileri Kongresi ve Sergisi, Denizli, 28-30 Eylül.

Trivedi, C., Iliev, I., Gunnar, O., Markov, Z., Engsdtom, F., Henning, L., 2020. Investigation of a Francis turbine during speed variation: Inception of cavitation. Renewable Energy, 166:147-162.

Tiwaria, G., Kumara, J., Prasad, B., Patel, K.V., 2020. Derivation of cavitation characteristics of a $3 \mathrm{MW}$ prototype Francis turbine through numerical hydro dynamic analysis. Proceding on Science Direct, 26(2):1439-1448.

Unterluggauer, J., Doujak, E., Bauer, C., 2019. Fatigue analysis of a prototype Francis turbine based on strain gauge measurements. Wasser Wirt Schaft, 109(1):66-71.

Valentín, D., Presas, A., Valero, C., Egusquiza, M., Egusquiza, E., 2019. Detection of hydraulic phenomena in francis turbines with different sensors. Sensors, 19(18):1-25.

Yu, A., Zou, Z., Zhou, D., Zheng, Y., Luo, X., 2020. Investigation of the correlation mechanism between cavitation rope behavior and pressure fluctuations in a hydraulic türbine. Renewable Energy, 147(1):1199-1208.

Ylönen, M., Saarenrinne, P., Miettinen, J., Franc, J., Fivel, M., Nyyssönen, T., 2018. Cavitation erosion resistance assessment and comparison of three francis turbine runner materials. Materials Performance and Characterization, 7(5):1107-1126.

Zhang, L., Wu, Q., Ma, Z., Wang, X., 2019. Transient vibration analysis of unit-plant structure for hydropower station in sudden load increasing process. Mechanical Systems and Signal Processing, 120:486-504.

Zhang, M., Valentín, D., Valero, C., Egusquiza, M., Egusquiza, E., 2019. Failure investigation of a Kaplan turbine blad. Engineering Failure Analysis, 97:690-700.

Qadir, Z., Abujubbeh, M., Mariam, A., Fahrioglu, M., Batunlu,C., 2019. Hydropower capacity of different power sectors in Pakistan. 1st Global Power, Energy and Communication Conference (GPECOM), Nevşehir, Turkey, 12-15 July.

URL1, 2020. https://commons.wikimedia.org/wiki/File :What_is_Pelton_Turbine.jpg, 19 Ağustos 2020.

URL-2,2020.http://www.hidropower.si/portfolio-items/ka plan-turbines/\#iLightbox[gallery261]/0, 20 Ağustos 2020.

URL-3, 2020. http://www.voith.com/caen/m_vh_francis_ turbine.png,25 Ağustos 2020. 